\title{
Gut morphology and hepatic oxidative status of European sea bass (Dicentrarchus labrax) juveniles fed plant feedstuffs or fishmeal-based diets supplemented with short-chain fructo-oligosaccharides and xylo-oligosaccharides
}

\author{
Inês Guerreiro $^{1,2}$, Ana Couto ${ }^{1 *}$, Amalia Pérez-Jiménez ${ }^{1,3}$, Aires Oliva-Teles ${ }^{1,2}$ and Paula Enes ${ }^{1}$ \\ ${ }^{1}$ Centro Interdisciplinar de Investigação Marinha e Ambiental (CIIMAR/CIMAR), Universidade do Porto, Rua dos Bragas 289, \\ 4050-123 Porto, Portugal \\ ${ }^{2}$ Departamento de Biologia, Faculdade de Ciências, Universidade do Porto, Rua do Campo Alegre s/n Ed FC4, 4169-007 Porto, \\ Portugal \\ ${ }^{3}$ Departamento de Zoología, Facultad de Ciencias, Universidad de Granada, Campus Fuentenueva s/n 18071 Granada, \\ Spain \\ (Submitted 5 May 2015 - Final revision received 22 August 2015 - Accepted 26 August 2015 - First published online 5 October 2015)
}

\section{Abstract}

The effects of short-chain fructo-oligosaccharides (scFOS) and xylo-oligosaccharides (XOS) on gut morphology and hepatic oxidative status were studied in European sea bass juveniles weighing $60 \mathrm{~g}$. Fish were fed diets including fishmeal (FM diets) or plant feedstuffs (PF diets; $30 \mathrm{FM}: 70 \mathrm{PF}$ ) as main protein sources (control diets). Four other diets were formulated similar to the control diets but including $1 \%$ scFOS or $1 \%$ XOS. At the end of the trial, fish fed PF-based diets presented histomorphological alterations in the distal intestine, whereas only transient alterations were observed in the pyloric caeca. Comparatively to fish fed FM-based diets, fish fed PF diets had higher liver lipid peroxidation (LPO), superoxide dismutase (SOD) and catalase (CAT) activities, and lower glutathione peroxidase, glutathione reductase and glucose 6-phosphate dehydrogenase activities. In fish fed the PF diets, prebiotic supplementation decreased SOD activity and XOS supplementation further decreased CAT activity. In fish fed the FM diets, XOS supplementation promoted a reduction of all antioxidant enzyme activities. Overall, dietary XOS and scFOS supplementation had only minor effects on gut morphology or LPO levels. However, dietary XOS reduced antioxidant enzymatic activity in both PF and FM diets, which indicate a positive effect on reduction of hepatic reactive oxygen species production.

\section{Key words: Antioxidant defences: European sea bass: Fish health: Intestinal histology: Plant feedstuffs: Prebiotics}

To promote a sustainable aquaculture production, alternatives to fishmeal (FM) and fish oil are needed, as these commodities are still major protein and lipid sources in commercial aquafeeds for carnivorous species ${ }^{(1)}$. Plant feedstuffs (PF) are nowadays the more available alternatives to FM, and overcome problems associated with fish by-products such as organic and inorganic contaminants, shortage of supply and net effect of demand-and-supply economics. However, PF usually contain anti-nutritional factors that may limit their use in aquafeeds ${ }^{(1,2)}$.

Prebiotics are defined as ingredients that are not digested by the host but that are fermented by bacteria present in the gut, therefore promoting bacteria growth and/or activity ${ }^{(3)}$. Some of the beneficial effects of prebiotics in fish are improved growth rate, feed efficiency (FE), feed digestibility, fish survival, immunological status and resistance to bacterial and viral diseases $^{(4-7)}$. Fructo-oligosaccharides (FOS) have already been evaluated as prebiotic in fish, but xylo-oligosaccharides (XOS) remain barely studied ${ }^{(4-7)}$. FOS are composed by short and medium chains of $\beta$-D-fructans in which fructosyl units are bound by $\beta$-(2-1) glycosidic linkages attached to a terminal glucose unit ${ }^{(6)}$. Short-chain fructo-oligosaccharides (scFOS) have a chemical composition similar to that of FOS but a smaller degree of polymerisation (between 1 and $5^{(8)}$ ). XOS are composed of xylose-based oligomers varying in the degree of polymerisation. Most of these oligomers consist of ester-linked phenolic acids such as ferulic, coumaric and caffeic acids ${ }^{(9,10)}$.

Abbreviations: CAT, catalase; DI, distal intestine; FM, fishmeal; FMC diet, FM control diet; FOS, fructo-oligosaccharides; G6PD, glucose 6-phosphate dehydrogenase; GPX, glutathione peroxidase; GR, glutathione reductase; LPO, lipid peroxidation; MOS, mannan-oligosaccharides; PC, pyloric caeca; PF, plant feedstuffs; ROS, reactive oxygen species; SBM, soyabean meal; scFOS, short-chain fructo-oligosaccharides; SOD, superoxide dismutase; XOS, xylooligosaccharides.

*Corresponding author: A. Couto, fax +351 220402 789, email acouto@fc.up.pt 
In fish fed diets containing plant ingredients, supplementation with prebiotics, namely mannan-oligosaccharides (MOS), trans-galacto-oligosaccharides (GOS) and FOS, improved intestinal morphology, by increasing gut absorptive area, microvilli density and height, and villi structure complexity ${ }^{(11-14)}$. In rats fed XOS-supplemented diets, total intestine weight increased relative to body weight, indicating augmented epithelial cell proliferation ${ }^{(15)}$. Up to now, there are, however, no studies accessing XOS effects on fish intestinal morphology.

$\mathrm{PF}$ and prebiotics were both reported to affect reactive oxygen species (ROS) generation in fish, decreasing oxidative damage and/or increasing antioxidant potential ${ }^{(16-21)}$. Prebiotics such as inulin were even reported as antioxidants, with ROS scavenging ability ${ }^{(22,23)}$. FOS was already reported as having antioxidant activity in fish, although mechanisms beyond that effect were not yet clarified ${ }^{(21,24)}$. XOS has ferulic acid in its composition, which was reported as having a very strong antioxidant activity ${ }^{(25)}$, and studies in mammals showed that XOS decreased lipid peroxidation (LPO) and modulated antioxidant enzymatic activity ${ }^{(26-28)}$. However, XOS antioxidant potential has not yet been assessed in fish.

Thus, the present work aimed to evaluate the effect of dietary scFOS and XOS supplementation in gut morphology and hepatic oxidative status of European sea bass (Dicentrarchus labrax) fed FM- or PF-based diets. This will contribute to elucidate the potential of prebiotics to mitigate some of the negative effects on fish health of using PF-based diets.

\section{Methods}

\section{Diets}

Two control diets were formulated to be isoproteic ( $46 \%$ crude protein) and isolipidic (15\% crude lipid). One diet included FM as the main protein source (FM control diet: FMC diet) and the other diet included FM and PF (soyabean meal (SBM), wheat meal, wheat gluten and maize gluten) to provide a protein source ratio of $30 \mathrm{FM}: 70 \mathrm{PF}$ (PF control diet: PFC diet). In both diets, cod liver oil was the main lipid source. Four other diets were formulated identical to the controls but including $1 \%$ commercial prebiotics: scFOS (PROFEED Maxflow; Jefo) or XOS (Qingdao FTZ United International Inc.), replacing $\alpha$-cellulose (diets PFFOS, PFXOS, FMFOS and FMXOS). All dietary ingredients were finely ground, well mixed and dry extruded in a laboratory pellet mill (California Pellet Mill) through a 3-mm die. The pellets were then dried in an oven $\left(40^{\circ} \mathrm{C}\right)$ for $24 \mathrm{~h}$ and stored in plastic containers until use. Ingredients and proximate composition of the experimental diets are presented in Table 1.

\section{Animals and experimental conditions}

The experiment was directed by FELASA category C certified scientists, and all procedures were conducted according to the European Union Directive 2010/63/EU on the protection of animals for scientific purposes. The growth trial was performed at the Marine Zoology Station, Porto University, Portugal, in a thermoregulated recirculating water system equipped with fibreglass tanks (100 litre capacity) supplied with continuous flow of filtered seawater $(6.0 \mathrm{l} / \mathrm{min})$, temperature regulated to 25.0 (SEM 1.0$)^{\circ} \mathrm{C}$, salinity of 36.0 (SEM $1.0 \mathrm{~g} / \mathrm{l}$ and dissolved oxygen kept near saturation $(7 \cdot 0 \mathrm{mg} / \mathrm{l})$.

European sea bass juveniles (D. labrax) were obtained from a commercial fish farm (Maresa S.A.) and after transportation to the experimental facilities fish were submitted to a quarantine period of $15 \mathrm{~d}$. During that period fish were fed with a commercial diet ( $48 \%$ protein, $11 \%$ lipids, $5 \%$ starch; A. Coelho \& Castro Lda). Thereafter, eighteen groups of twenty fish with an initial mean body weight of $60 \mathrm{~g}$ were established and each diet was randomly assigned to triplicate tanks. The trial lasted 7 weeks, and during that period fish were fed by hand, $6 \mathrm{~d} /$ week, until visual satiation. No mortality occurred during the trial.

\section{Sampling}

After 7 and $15 \mathrm{~d}$ of the start of the feeding trial and at the end of the trial, three fish from each tank were randomly selected $2 \mathrm{~h}$ after the morning meal and euthanised with a sharp blow to the head. Fish were dissected on chilled trays and the digestive tract was freed from the adjacent adipose and connective tissues. Two pyloric caeca (PC) and a section of the distal intestine (DI, distinguished from the mid intestine by an enlarged diameter and darker mucosa) were sampled for histological evaluation. The samples were rinsed in PBS, carefully blotted dry with a paper towel, immediately fixed in phosphatebuffered formalin ( $4 \%, \mathrm{pH} 7.4$ ) for $24 \mathrm{~h}$ and subsequently transferred to ethanol (70\%) until further processing. At the end of the trial, livers were also sampled from the same fish, immediately frozen in liquid $\mathrm{N}_{2}$ and stored at $-80^{\circ} \mathrm{C}$ until measurement of enzymes activities and LPO levels.

\section{Proximate analysis of the diets}

Chemical analyses of the diets were performed following the Association of Official Analytical Chemists methods ${ }^{(29)}$. Energy content was determined by direct combustion in an adiabatic bomb calorimeter (PARR model 1261; PARR Instruments) and starch content was analysed according to Beutler ${ }^{(30)}$.

\section{Histological processing and morphological evaluation}

PC and DI samples were processed and sectioned using standard histological techniques, and sections were stained with haematoxylin-eosin. Blind evaluation of histological preparations was performed with particular attention given to any inflammatory changes ${ }^{(31,32)}$, namely shortening, widening and fusion of intestinal folds $(\mathrm{FH})$, changes in enterocytes nucleous (ENT) and supranuclear absorptive vacuolisation (SNV), connective tissue hyperplasia in the lamina propria (LP) and submucosa (SM), and infiltration of inflammatory cells (intraepithelial leucocyte (IEL)). A continuous scale scoring system was used as described by Penn et al. ${ }^{(33)}$, with the range of tissue scores set at $0-5$. The overall value of histomorphological alterations was calculated by averaging scores of the separate parameters described above. Images were acquired with the Zen software (Blue edition; Zeiss). 
Table 1. Ingredient composition and proximate analysis of the experimental diets

\begin{tabular}{|c|c|c|c|c|c|c|}
\hline & \multicolumn{6}{|c|}{ Diets } \\
\hline & PFC & PFFOS & PFXOS & FMC & FMFOS & FMXOS \\
\hline \multicolumn{7}{|l|}{ Ingredients (\% dry-weight basis) } \\
\hline Fishmeal $^{*}$ & $15 \cdot 6$ & $15 \cdot 6$ & $15 \cdot 6$ & $59 \cdot 2$ & $59 \cdot 2$ & $59 \cdot 2$ \\
\hline Soluble fish protein concentrate & $5 \cdot 0$ & $5 \cdot 0$ & $5 \cdot 0$ & $5 \cdot 0$ & $5 \cdot 0$ & $5 \cdot 0$ \\
\hline Soyabean mealł & $25 \cdot 0$ & $25 \cdot 0$ & $25 \cdot 0$ & - & - & - \\
\hline Wheat meal§ & $18 \cdot 3$ & $18 \cdot 3$ & $18 \cdot 3$ & - & - & - \\
\hline Wheat glutenll & $15 \cdot 0$ & $15 \cdot 0$ & $15 \cdot 0$ & - & - & - \\
\hline Maize gluten $\Upsilon$ & $5 \cdot 2$ & $5 \cdot 2$ & $5 \cdot 2$ & - & - & - \\
\hline Cod liver oil & 11.5 & 11.5 & 11.5 & $8 \cdot 9$ & 8.9 & 8.9 \\
\hline Pregelatinised maize starch ${ }^{\star \star}$ & - & - & - & $22 \cdot 4$ & $22 \cdot 4$ & $22 \cdot 4$ \\
\hline Fructo-oligosaccharide†† & - & 1.0 & - & - & $1 \cdot 0$ & - \\
\hline Xylo-oligosaccharide $\ddagger \ddagger$ & - & - & 1.0 & - & - & 1.0 \\
\hline Vitamin premix§§ & $1 \cdot 0$ & $1 \cdot 0$ & $1 \cdot 0$ & $1 \cdot 0$ & $1 \cdot 0$ & $1 \cdot 0$ \\
\hline Mineral premixIIII & $1 \cdot 0$ & 1.0 & $1 \cdot 0$ & 1.0 & $1 \cdot 0$ & $1 \cdot 0$ \\
\hline Choline chloride (50\%) & 0.5 & 0.5 & 0.5 & 0.5 & 0.5 & 0.5 \\
\hline$a$-Cellulose & $1 \cdot 0$ & - & - & $1 \cdot 0$ & - & - \\
\hline Binderף| & $1 \cdot 0$ & $1 \cdot 0$ & $1 \cdot 0$ & $1 \cdot 0$ & $1 \cdot 0$ & $1 \cdot 0$ \\
\hline \multicolumn{7}{|c|}{ Proximate analyses (\% dry-weight basis) } \\
\hline DM & 89.5 & $89 \cdot 1$ & $89 \cdot 8$ & $88 \cdot 6$ & 93 & $96 \cdot 1$ \\
\hline $\mathrm{CP}$ & $45 \cdot 7$ & $45 \cdot 9$ & 46 & $46 \cdot 2$ & $46 \cdot 7$ & $47 \cdot 4$ \\
\hline Crude fat & $14 \cdot 9$ & $15 \cdot 4$ & $15 \cdot 2$ & $15 \cdot 4$ & 15 & $15 \cdot 1$ \\
\hline Ash & 6.9 & 6.9 & 6.9 & $12 \cdot 5$ & $12 \cdot 6$ & $12 \cdot 7$ \\
\hline Starch & $12 \cdot 6$ & $14 \cdot 3$ & $13 \cdot 2$ & $19 \cdot 7$ & $20 \cdot 2$ & 19 \\
\hline Gross energy (kJ/g DM) & $22 \cdot 9$ & $22 \cdot 7$ & 23.5 & $21 \cdot 1$ & 20.9 & $21 \cdot 2$ \\
\hline
\end{tabular}

PFC, plant feedstuff control diet; PFFOS, plant feedstuff fructo-oligosaccharides; PFXOS, plant feedstuff xylo-oligosaccharides; FMC, fishmeal control diet; FMFOS, fishmeal fructooligosaccharides; FMXOS, fishmeal xylo-oligosaccharides; CP, crude protein; GL, gross lipid.

* Inproquise (CP: $70 \cdot 1 \%$ DM; GL: $8.8 \%$ DM).

† Sopropèche G (CP: $79.4 \%$ DM; GL: $19.7 \%$ DM).

‡ Sorgal, S.A. (CP: $50.5 \%$ DM; GL: $1.7 \%$ DM).

$\S$ Sorgal, S.A. (CP: $11.8 \%$ DM; GL: $1.9 \%$ DM).

II Sorgal, S.A. (CP: $82.8 \%$ DM; GL: $1.9 \%$ DM).

I Sorgal, S.A. (CP: $65.7 \%$ DM; GL: $3.5 \%$ DM)

** C-Gel Instant - 12016; Cerestar.

†† PROFEED Maxflow; Jefo.

㧊 Qingdao FTZ United International Inc.

$\S \S$ Vitamins (mg/kg diet): retinol, 6.19; cholecalciferol, 0.04; $\alpha$-tocopherol, 35; menadion sodium bisulphate, 10; thiamine, 15; riboflavin, 25; Ca pantothenate, 50; nicotinic acid, 200; pyridoxine, 5; folic acid, 10; cyanocobalamin, 0.02; biotin, 1.5; ascorbyl monophosphate, 50; inositol, 400.

IIII Minerals (mg/kg diet): cobalt sulphate, 1.91; copper sulphate, 19.6; iron sulphate, 200; sodium fluoride, 2.21; potassium iodide, 0.78 ; magnesium oxide, 830; manganese oxide,

26; sodium selenite, 0.66 ; zinc oxide, 37.5; dibasic calcium phosphate, 5.93 (g/kg diet); potassium chloride, 1.15 (g/kg diet); sodium chloride, 0.44 (g/kg diet).

ๆी Aquacube (guar gum, polymethyl carbamide, manioc starch blend, hydrated calcium phosphate) (Agil).

\section{Enzyme activity}

Liver samples were homogenised on ice in five volumes of ice-cold $100 \mathrm{~mm}$-Tris- $\mathrm{HCl}$ buffer containing $0 \cdot 1 \mathrm{mm-EDTA}$ and $0 \cdot 1 \%(\mathrm{v} / \mathrm{v})$ Triton $\mathrm{X}-100, \mathrm{pH} 7 \cdot 8$. Homogenates were centrifuged at $30000 \mathrm{~g}$ for $30 \mathrm{~min}$ at $4^{\circ} \mathrm{C}$, and the resultant supernatants were separated in aliquots and stored at $-80^{\circ} \mathrm{C}$ until use. All enzyme assays were carried out at $25^{\circ} \mathrm{C}$ in a microplate reader (ELx808; BioTek Instruments). The optimal substrate and protein concentrations for measurement of maximal activity for each enzyme were established by preliminary assays. The molar extinction coefficients used for $\mathrm{H}_{2} \mathrm{O}_{2}$ and NADPH were 0.039 and $6.22 \mathrm{~mm}^{-1} \times \mathrm{cm}^{-1}$, respectively. Superoxide dismutase (SOD, EC 1.15.1.1), catalase (CAT, EC 1.11.1.6), glutathione peroxidase (GPX, EC 1.11.1.9), glutathione reductase (GR; EC 1.6.4.2) and glucose 6-phosphate dehydrogenase (G6PD, EC 1.1.1.49) activities were determined as described by Enes et $a l^{(34)}$. Protein concentration in the homogenates was determined by the Bradford method ${ }^{(35)}$ using the Sigma protein assay kit (ref. B6916) (Sigma-Aldrich Química, S.L.) with bovine serum albumin as a standard.
Enzyme activity was expressed as units (SOD, CAT) or milliunits (GPX, GR and G6PD) per $\mathrm{mg}$ of hepatic soluble protein. Except for SOD, one unit of enzyme activity was defined as the amount of enzyme required to transform $1 \mu \mathrm{mol}$ of substrate/min under the assay conditions. One unit of SOD activity was defined as the amount of enzyme necessary to produce $50 \%$ inhibition of the ferricytochrome c reduction rate.

\section{Lipid peroxidation}

Malondialdehyde (MDA) concentration was used as a marker of LPO level in the liver. In the presence of thiobarbituric acid, MDA reacts producing coloured thiobarbituric acid-reacting substances that were measured as described by Enes et $a l{ }^{(34)}$. Results were expressed as nmol MDA per $\mathrm{g}$ of wet tissue, calculated from a calibration curve.

\section{Statistical analysis}

Data analysis was done by two-way ANOVA using SPSS 21 software package (SPSS ${ }^{\circledR}$ Inc.). Previous to ANOVA, data were 
tested for normality and homogeneity (Shapiro-Wilk and Levene's tests, respectively) and when necessary transformed to achieve ANOVA assumptions. When significant interaction between factors were found, one-way ANOVA was performed within each protein source (PF and FM). Significant differences among means were determined with the Tukey's multiple range test. Histological data were neither normal nor homogeneous and could not be normalised, and they were analysed by the Kruskal-Wallis non-parametric test followed by pairwise comparisons. For all data, the probability level for rejection of the null hypotheses was 0.05.

\section{Results}

\section{Growth performance, feed efficiency and feed intake}

Growth performance was not the aim of this study, and it was presented in detail elsewhere ${ }^{(36)}$. Briefly, protein source had no effect on fish growth, but feed intake (FI) was higher and FE was lower in fish fed PF diets (Table 2). Prebiotic supplementation had no effect on growth of fish fed FM but XOS improved growth performance in fish fed PF diets. Prebiotic supplementation had no effect on FI and FE, independently of dietary protein source.

\section{Gut morphology}

Mean scores of the average of the separate parameters (FH, LP, SM, IEL, ENT and SNV) evaluated in PC and DI during the course of the trial are presented in Table 3 . (Mean values with their pooled standard errors; $n 3)^{(36)}$
No histomorphological alterations were observed with time in fish fed the FM-based diets. In fish fed the PF-based diets, histomorphological alterations with time were significant in the $\mathrm{PC}$, but not in the DI.

In the PC, replacement of FM by PF resulted in an increase of mean scores of the evaluated parameters, and this increase was significantly higher after $15 \mathrm{~d}$ of feeding the experimental diets. Addition of FOS and XOS to the diets had no effect on PC morphology relatively to the respective control diets. Further, at $15 \mathrm{~d}$ of feeding, the mean scores of the evaluated parameters in fish fed the PFXOS diet was not different from that of the FMC diet. Histomorphological alterations observed in PF groups were transient, as by the end of the trial mean scores returned to values similar to the FMC diet. Overall, the most relevant observation in $\mathrm{PC}$ was the presence of enterocyte swelling (Fig. 1) in fish fed diets containing PF, which resulted in higher ENT and SNV scores in the mentioned groups (for both characteristics: $P<0.001, P<0.001$ and $P=0.001$ at time points 7,15 and final, respectively). To allow a better visualisation of the data, a graph with the several histological parameters evaluated in the PC was made (Fig. 2(a)). As no major differences were observed regarding the effects of prebiotics, and to simplify visualisation, data were pooled and presented only as FM and PF groups.

$\mathrm{PF}$ diets induced more pronounced effects in DI histomorphology, as denoted by the higher mean scores. Replacement of FM by PF resulted in an increase of mean scores of the evaluated parameters in the DI at all sampling days. The addition of prebiotics to PF diets did not ameliorate the negative effects in DI histomorphology.

Table 2. Growth performance and feed utilisation efficiency of European sea bass fed the experimental diets

\begin{tabular}{|c|c|c|c|c|c|c|c|c|c|c|}
\hline \multirow[b]{2}{*}{ Diets } & \multirow[b]{2}{*}{ PFC } & \multirow[b]{2}{*}{ PFFOS } & \multirow[b]{2}{*}{ PFXOS } & \multirow[b]{2}{*}{ FMC } & \multirow[b]{2}{*}{ FMFOS } & \multirow[b]{2}{*}{ FMXOS } & \multirow[b]{2}{*}{ Pooled SEM } & \multicolumn{3}{|c|}{ Two-way ANOVA* } \\
\hline & & & & & & & & Protein & Prebiotic & Interaction \\
\hline Final body weight (g) & $98 \cdot 4^{a}$ & $101 \cdot 0^{\mathrm{a}, \mathrm{b}}$ & $108 \cdot 5^{\mathrm{b}}$ & $107 \cdot 0$ & $106 \cdot 8$ & $103 \cdot 6$ & 1.20 & 0.136 & 0.410 & 0.038 \\
\hline Feed intake $(\mathrm{g} / \mathrm{kg} \mathrm{ABW}$ per d) $\dagger$ & $15 \cdot 9$ & $16 \cdot 7$ & $16 \cdot 5$ & $14 \cdot 3$ & $14 \cdot 4$ & $15 \cdot 0$ & 0.26 & $<0.001$ & 0.130 & 0.372 \\
\hline FE $\ddagger$ & 0.66 & 0.61 & 0.68 & 0.79 & 0.80 & 0.76 & 0.02 & $<0.001$ & 0.744 & 0.039 \\
\hline
\end{tabular}

a,b Mean values within the same line with unlike superscript letters were significantly different $(P<0.05)$.

* Two-way ANOVA: if interaction was significant, one-way ANOVA was performed for prebiotics within each protein source.

$\dagger$ Average body weight (ABW): initial body weight + final body weight/2.

$\ddagger$ Feed efficiency (FE): wet weight gain/dry feed intake

Table 3. Intestinal histology (pyloric caeca (PC) and distal intestine (DI)) of European sea bass fed the experimental diets for 7 and $15 \mathrm{~d}$ and by the end of the trial (final)*

(Mean values with their pooled standard errors; $n$ 9)

\begin{tabular}{|c|c|c|c|c|c|c|c|c|}
\hline Sections & Time & PFC & PFFOS & PFXOS & FMC & FMFOS & FMXOS & Pooled SEM \\
\hline \multirow[t]{3}{*}{ PC } & $7 d$ & $B_{1.83}$ & $B_{1.62}$ & $B_{1.51}$ & $1 \cdot 14$ & $1 \cdot 18$ & 1.26 & 0.28 \\
\hline & $15 d$ & ${ }^{\mathrm{A}} 1.43^{\mathrm{b}, \mathrm{c}}$ & $\mathrm{B}_{1.80^{\mathrm{C}}}$ & $\mathrm{A}, \mathrm{B}_{1} \cdot 36^{\mathrm{a}, \mathrm{b}, \mathrm{c}}$ & $1.17^{\mathrm{a}}$ & $1 \cdot 21^{a, b}$ & $1 \cdot 20^{\mathrm{a}, \mathrm{b}}$ & 0.24 \\
\hline & Final & $\mathrm{A}_{1} \cdot 36^{\mathrm{b}}$ & $\mathrm{A}_{1} \cdot 32^{\mathrm{a}, \mathrm{b}}$ & ${ }^{A} 1 \cdot 23^{a, b}$ & $1 \cdot 26^{\mathrm{a}, \mathrm{b}}$ & $1 \cdot 19^{\mathrm{a}}$ & $1 \cdot 18^{\mathrm{a}, \mathrm{b}}$ & 0.07 \\
\hline \multirow[t]{3}{*}{ DI } & $7 d$ & $2 \cdot 13^{\mathrm{C}}$ & $2.09^{c}$ & $2 \cdot 11^{\mathrm{c}}$ & $1 \cdot 12^{\mathrm{a}}$ & $1.55^{\mathrm{a}, \mathrm{b}, \mathrm{c}}$ & $1.42^{\mathrm{a}, \mathrm{b}}$ & 0.42 \\
\hline & $15 d$ & $2 \cdot 13^{\mathrm{c}, \mathrm{d}}$ & $2 \cdot 32^{d}$ & $2 \cdot 06^{\mathrm{b}, \mathrm{c}, \mathrm{d}}$ & $1 \cdot 10^{a}$ & $1.43^{a, b, c}$ & $1.37^{a, b}$ & 0.50 \\
\hline & Final & $2 \cdot 02^{b, c}$ & $2 \cdot 21^{\mathrm{C}}$ & $2 \cdot 00^{\mathrm{b}, \mathrm{c}}$ & $1 \cdot 16^{a}$ & $1.54^{a, b}$ & $1.50^{\mathrm{a}, \mathrm{b}}$ & 0.40 \\
\hline
\end{tabular}

PFC, plant feedstuff control diet; PFFOS, plant feedstuff fructo-oligosaccharides; PFXOS, plant feedstuff xylo-oligosaccharides; FMC, fishmeal control diet; FMFOS, fishmeal fructooligosaccharides; FMXOS, fishmeal xylo-oligosaccharides.

$A, B, a, b, c, d$ Mean values with unlike superscript lowercase letters stand for statistical differences across dietary groups within each sampling day; mean values with unlike superscript uppercase letters stand for statistical differences for each parameter with time, as determined by the Kruskal-Wallis all pairwise comparisons $(P<0 \cdot 05)$.

* Mean scores were calculated by averaging the scores of the separate parameters evaluated (shortening, widening and fusion of intestinal folds, changes in enterocytes nucleous and supranuclear absorptive vacuolization, connective tissue hyperplasia in the lamina propria and submucosa, and infiltration of inflammatory cells). Score from 0 to 5 , with 5 indicating major alterations. 
(a)

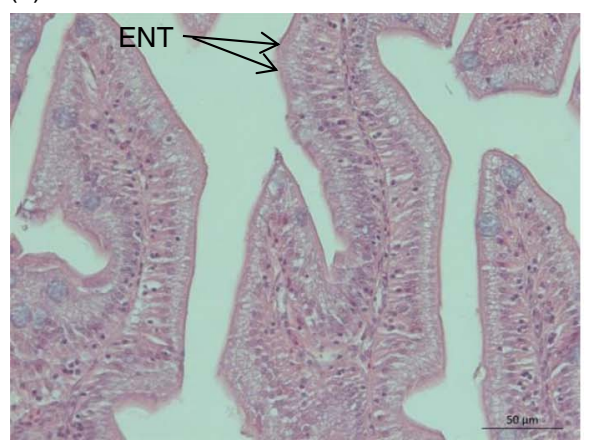

(b)

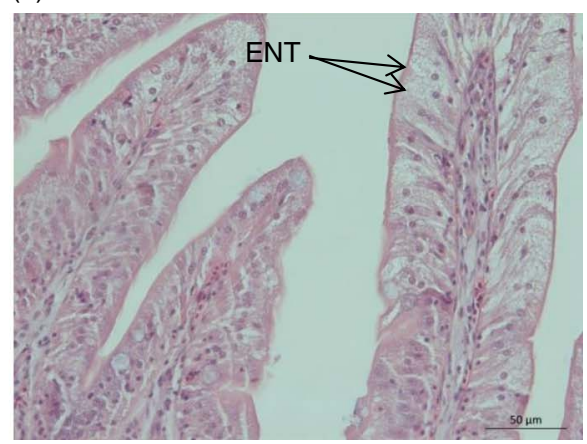

Fig. 1. Detail of enterocyte nucleousswelling (ENT) in the pyloric caeca of fish fed fishmeal xylo-oligosaccharides (a) and plant feedstuff xylo-oligosaccharides (b) at time point $7 \mathrm{~d}$. Scale bar: $50 \mu \mathrm{m}$; haematoxylin-eosin staining.
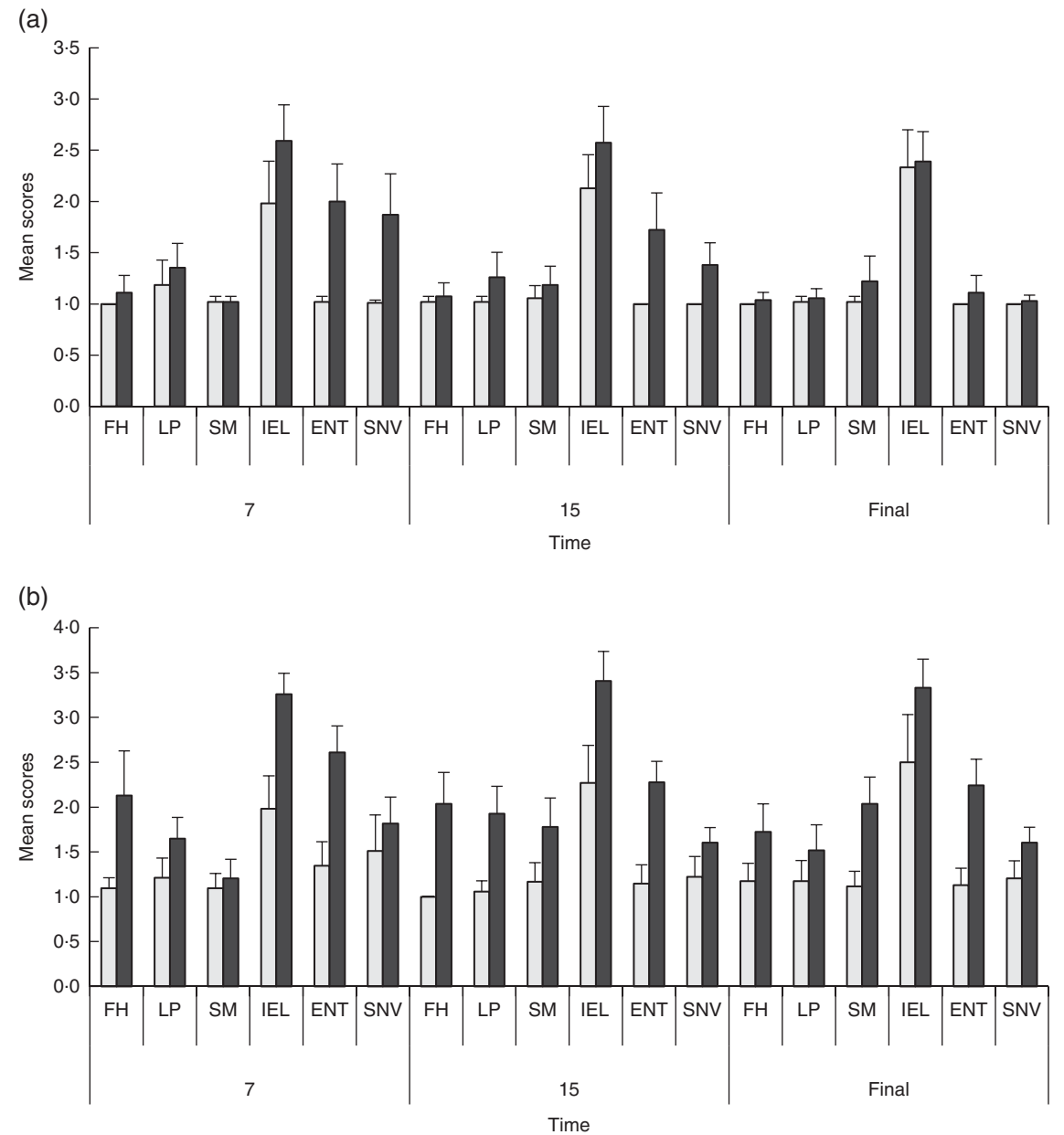

Fig. 2. Mean scores, with their standard errors for pyloric caeca (a) and distal intestine (b) of FH (shortening, widening and fusion of intestinal folds), LP (connective tissue hyperplasia in the lamina propria), SM (connective tissue hyperplasia in the submucosa), IEL (infiltration of inflammatory cells), ENT (changes in enterocytes nucleous) and SNV (changes in supranuclear absorptive vacuolisation). As no major differences were observed regarding the effects of prebiotics, and to simplify visualisation, data were pooled and presented only as FM ( $\square$ ) and PF ( $\square$ ) groups. Data are separated for sea bass fed the experimental diets for 7 and $15 \mathrm{~d}$ and by the end of the trial (final). Score from 0 to 5 , with 5 indicating major alterations.

The most pronounced histological alterations observed in the DI of fish fed PF diets (Fig. 3) were as follows: decreased height of the mucosal folds $(P<0.001, P<0.001$ and $P=0.004$ in time points 7,15 and final, respectively), increased number of
IEL $(P<0.001, P<0.001$ and $P<0.001$ in time points 7,15 and final, respectively) and abnormal size variation of SNV ( $P=0.013, P=0.002$ and $P=0.001$ in time points 7,15 and final, respectively). As explained above, a graph was also made for 
(a)

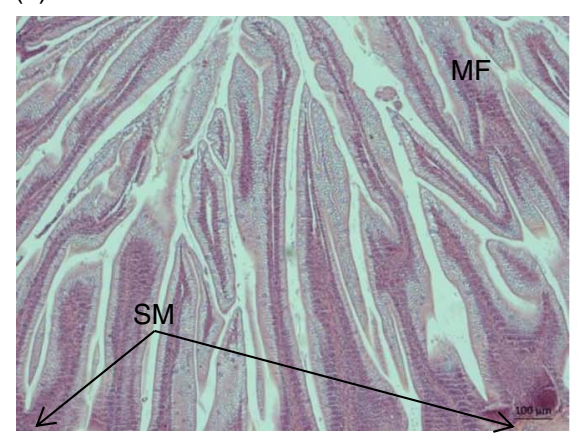

(c)

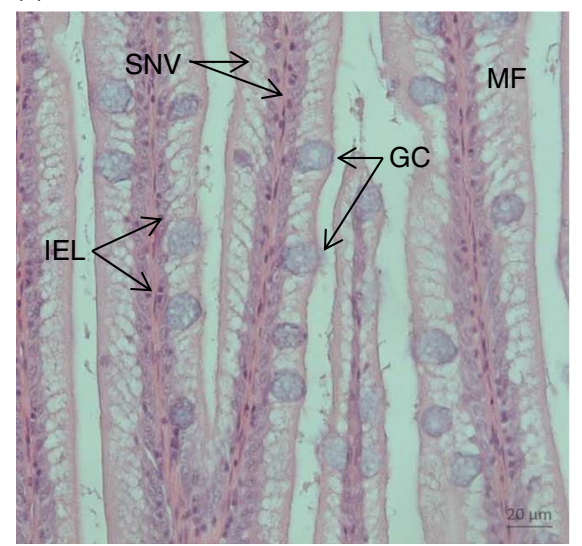

(b)

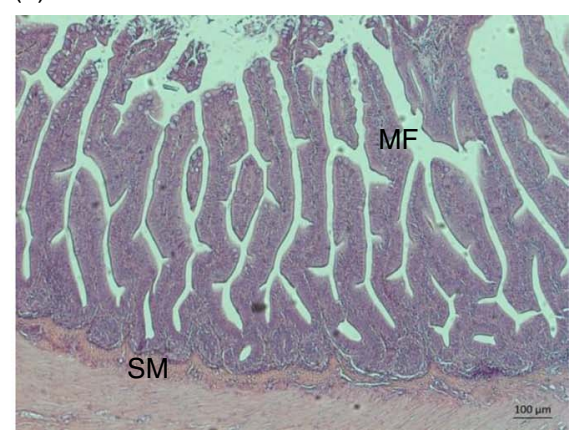

(d)

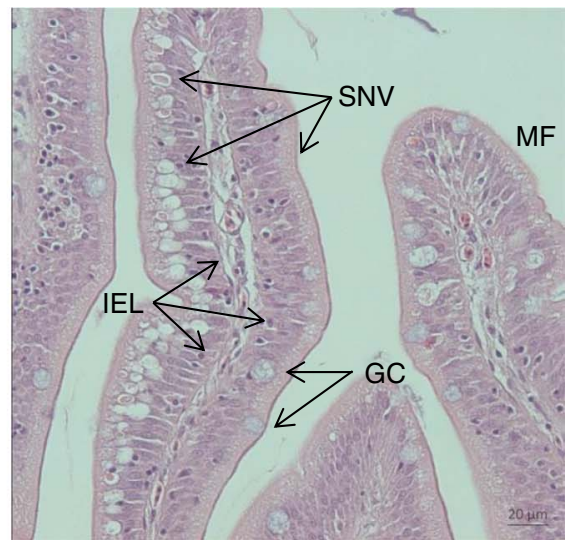

Fig. 3. Distal intestine alterations in fish fed FM control diet (a, c) and PF control diet (PFC) (b, d), showing decreased fold height, increased width of the lamina propria and intraepithelial leucocytes (IEL), as well as abnormal enterocyte vacuolisation and nucleous position in PFC group at time point $15 \mathrm{~d}$. MF, mucosal fold; SM, submucosa; GC, goblet cell; SNV, supranuclear vacuole. Scale bars: $100 \mu \mathrm{m}$ (a, b); $20 \mu \mathrm{m}$ (c, d); haematoxylin-eosin staining.

Table 4. Specific activities of hepatic antioxidant enzymes and lipid peroxidation (LPO) levels of European sea bass fed the experimental diets* (Mean values with their pooled standard errors; $n$ 9)

\begin{tabular}{|c|c|c|c|c|c|c|c|c|c|c|}
\hline \multirow[b]{2}{*}{ Diets } & \multirow[b]{2}{*}{ PFC } & \multirow[b]{2}{*}{ PFFOS } & \multirow[b]{2}{*}{ PFXOS } & \multirow[b]{2}{*}{ FMC } & \multirow[b]{2}{*}{ FMFOS } & \multirow[b]{2}{*}{ FMXOS } & \multirow[b]{2}{*}{ Pooled SEM } & \multicolumn{3}{|c|}{ Two-way ANOVA† } \\
\hline & & & & & & & & Protein & Prebiotic & Interaction \\
\hline SOD & $219^{c}$ & $190^{\mathrm{b}}$ & $165^{\mathrm{a}}$ & $168^{a, b}$ & $182^{\mathrm{b}}$ & $149^{a}$ & 3.7 & $<0.001$ & $<0.001$ & 0.001 \\
\hline CAT & 191 & 203 & 173 & 145 & 148 & 127 & $4 \cdot 7$ & $<0.001$ & 0.004 & 0.822 \\
\hline GPX & 65 & 74 & 75 & $101^{b}$ & $85^{a, b}$ & $71^{a}$ & $2 \cdot 3$ & $<0.001$ & 0.065 & $<0.001$ \\
\hline GR & 1.91 & $2 \cdot 34$ & $2 \cdot 11$ & $3 \cdot 30^{b}$ & $3 \cdot 21^{\mathrm{b}}$ & $2 \cdot 32^{a}$ & 0.08 & $<0.001$ & $<0.001$ & $<0.001$ \\
\hline G6PD & $171^{a}$ & $211^{\mathrm{b}}$ & $173^{a}$ & $289^{b}$ & $320^{c}$ & $240^{a}$ & $8 \cdot 3$ & $<0.001$ & $<0.001$ & 0.006 \\
\hline LPO & $12 \cdot 62$ & $10 \cdot 89$ & $12 \cdot 16$ & $9 \cdot 25$ & $9 \cdot 38$ & $9 \cdot 36$ & 0.25 & $<0.001$ & 0.123 & 0.072 \\
\hline
\end{tabular}

PFC, plant feedstuff control diet; PFFOS, plant feedstuff fructo-oligosaccharides; PFXOS, plant feedstuff xylo-oligosaccharides; FMC, fishmeal control diet; FMFOS, fishmeal fructooligosaccharides; FMXOS, fishmeal xylo-oligosaccharides; SOD, superoxide dismutase; CAT, catalase; GPX, glutathione peroxidase; GR, glutathione reductase; G6PD, glucose 6-phosphate dehydrogenase.

a,b,c Mean values within the same line with unlike superscript letters are significantly different $(P<0.05)$.

* SOD and CAT are expressed as U/mg protein. GPX, GR and G6PD are expressed as $\mathrm{mU} / \mathrm{mg}$ protein. LPO is expressed as nmol malondialdehyde/g tissue.

$\dagger$ Two-way ANOVA: for CAT, two-way ANOVA results showed significant differences among control, fructo-oligosaccharides and xylo-oligosaccharides, regardless of protein source, being Tukey's test results as b-b-a, respectively. For other parameters, if interaction was significant, one-way ANOVA was performed for prebiotics within each protein source.

the DI portion (Fig. 2(b)). Opposite to what was observed in PC, histological alterations did not recede and were similar at days 7,15 and by the end of the trial.

\section{Antioxidant enzymatic activity and lipid peroxidation}

Antioxidant enzymatic activity and LPO levels at the end of the trial are present in Table 4 . Protein source affected all parameters analysed. LPO levels, SOD and CAT activities were higher, whereas GPX, GR and G6PD activities were lower in fish fed PF diets than the FM diets. LPO level and GPX activity were not affected by prebiotic incorporation, whereas CAT activity was decreased by XOS supplementation.

In fish fed $\mathrm{PF}$ diets, both scFOS and XOS decreased SOD activity, whereas in fish fed FM diets XOS led to a reduction of SOD, GPX, GR and G6PD enzymatic activities. Compared with the control groups, scFOS increased G6PD activity in both PF and FM diets. 


\section{Discussion}

A replacement of $95 \%$ of FM by PF in diets for European sea bass was already accomplished without affecting fish growth, diets digestibility or voluntary $\mathrm{FI}^{(37)}$. However, in that study authors did not perform intestinal histomorphology observations. However, it is well known that the anti-nutritional factors presented in PF, namely those present in SBM, can cause moderate and severe enteritis in fish ${ }^{(31,38-41)}$. In the present study, although no overt inflammation was observed, fish fed PF diets presented alterations in the DI histomorphology when compared with fish fed FMC diets. Such an effect may be related to the inclusion of $25 \%$ of SBM in the PF diets, as it was previously observed in Atlantic salmon (Salmo salar) ${ }^{(39,40)}$. However, it was previously reported in European sea bass that inclusion of $30 \% \mathrm{SBM}$ had no significant consequences in the DI histomorphology ${ }^{(42)}$. Thus, the DI modifications observed in the present study were more likely a consequence of the combination of different $\mathrm{PF}$, and thus different anti-nutrients, in the PF diets. Accordingly, Couto et al. ${ }^{(43)}$ fed European sea bass with two purified soyabean anti-nutrients, saponins and phytosterols, and observed no severe effects on fish gut histology, supporting the fact that the inflammation observed in the present study could be because of interaction/cumulative effects of anti-nutrients and PF sources.

In this study, the majority of permanent gut histological alterations were observed on the DI portion. A similar observation was reported by van den Ingh et al. ${ }^{(38)}$ in salmon fed diets in which FM was partially replaced by $30 \%$ full-fat SBM. The presence of inflammation only in the DI was related to the higher sensibility of this intestinal portion to PF anti-nutrients. In fact, the same was already reported in another study with salmon $^{(44)}$ and in European sea bass ${ }^{(43)}$.

With regard to the PC section, although at $15 \mathrm{~d}$ fish fed PFC diets presented higher mean scores for the evaluated parameters than fish fed the FMC diet, at the end of the trial no histomorphological differences between the two groups were found. These results indicate that fish were able to adapt to the high dietary PF levels, reversing the initial histomorphological alterations. Such recovery from previous histological alterations because of diet changes has already been reported for European sea bass ${ }^{(43)}$ and common carp (Cyprinus carpio $)^{(45)}$. Urán et al. ${ }^{(45)}$ hypothesised that this recovery was related to the omnivorous feeding habits of carp, making it prone to adapt to diets with high PF levels. This is not the case for sea bass, as it is a carnivorous species and thus does not feed on PF in nature. However, the present results indicate that European sea bass has higher tolerance for PF than salmon, which is also a carnivorous species. Indeed, salmon seems to be particularly intolerant to high levels of dietary PF. Actually, even rainbow trout (Oncorbynchus mykiss), which is also a carnivorous species that belongs to the same family as salmon, exhibits higher tolerance for SBM anti-nutritional factors ${ }^{(46)}$.

Although prebiotics such as MOS, GOS and FOS have been reported as increasing gut absorptive surface area and microvilli density and height in fish fed plant-based diets ${ }^{(11-14)}$, in the present study no histomorphological alterations were noticed in fish fed the PF diets. Other studies similar to the present one also reported no differences at optical microscopy level in the intestinal morphology of fish fed diets containing PF and prebiotics $^{(11,47,48)}$. Dimitroglou et al. ${ }^{(12)}$ fed gilthead sea bream (Sparus aurata) FM- and SBM-based diets supplemented with MOS, and also observed that MOS had no effect on the mucosal folds morphology of the anterior intestine. However, MOS appeared to improve the absorptive surface area in the posterior intestine of fish fed the FM diet, as denoted by higher perimeter of the intestinal lumen. However, using electron microscopy techniques, it became evident that MOS affected both anterior and posterior intestine at the ultrastructural level in fish fed FM- and SBM-based diets. As we did not assess the intestinal ultrastructure of fish intestine, it cannot be ruled out that histological alterations may have occurred at this level.

Differences between studies on the effects of prebiotics in gut histomorphology may also be related to prebiotic type, dosage, species assessed and age, rearing conditions, differences in gut microbiota or methodological approaches. For instance, Dimitroglou et al. ${ }^{(11)}$ showed that gut histology of fish fed the same prebiotic (MOS) and diet may change in the same species depending on fish age. Authors observed improvements in gut morphology, such as increased absorptive surface, microvilli density and length, of subadult rainbow trout fed MOS, whereas no effects were observed in juveniles.

It was previously reported in rainbow trout, Atlantic salmon, gilthead sea bream and European sea bass that PF can reduce oxidative damage in fish ${ }^{(16,17,20)}$. This may be linked to PF components with strong antioxidant activity, namely phenolic compounds, flavonoids, $\alpha$-tocopherol or astaxanthin ${ }^{(17,20)}$.

Although the PF used in the present study are rich sources of flavonoids (SBM) and phenolic compounds, mostly in the form of ferulic acid (maize and wheat meal) ${ }^{(49,50)}$, no improved antioxidant effect was observed in the PF diets. Indeed, fish fed PF diets presented higher hepatic LPO level than fish fed FM diets. Increased LPO occurs when ROS production is higher than ROS removal. SOD, which catalyses the dismutation of the superoxide anion $\left(\mathrm{O}_{2}{ }^{-}\right)$to molecular oxygen and $\mathrm{H}_{2} \mathrm{O}_{2}$, is the first enzyme responding to the presence of oxygen radicals, preventing the radical chain reaction initiated by $\mathrm{O}_{2}{ }^{-}$. In the present study, hepatic SOD activity was higher in fish fed PF diets, indicating that there was a rise of $\mathrm{O}_{2}{ }^{-}$generation in fish fed PF diets. Hepatic CAT activity was also increased, whereas hepatic GPX activity was lower in fish fed PF diets, indicating that CAT was the major route for reducing $\mathrm{H}_{2} \mathrm{O}_{2}$ to molecular oxygen and water. The different behaviour of the two peroxidation reduction routes may be related to the overall concentration of $\mathrm{H}_{2} \mathrm{O}_{2}$ generated, as it is known that CAT is more active when $\mathrm{H}_{2} \mathrm{O}_{2}$ production is high, whereas GPX is induced by low $\mathrm{H}_{2} \mathrm{O}_{2}$ levels ${ }^{(51)}$. Such low $\mathrm{H}_{2} \mathrm{O}_{2}$ levels are probably present in fish fed FM-based diets, as in this group significantly lower SOD activities were noticed. GR has a role in the modulation of GPX activity, as it catalyses the NADPH-dependent regeneration of $\mathrm{GSH}$ from GSSG generated by GPX ${ }^{(51)}$. Thus, and in order to maintain the GSSG:GSH ratio, higher hepatic GR activity was observed in fish fed FM diets because of the high GPX activity observed in fish fed those diets. Hepatic G6PD was also increased in fish fed FM diets, as it is involved in NADPH regeneration, which is a coenzyme required for GR activity ${ }^{(52,53)}$. 
Although LPO levels were unaffected by dietary prebiotic incorporation, XOS supplementation seemed to contribute to a reduction of overall ROS production, as CAT activity was lower in fish fed both PFXOS and FMXOS, and activities of GPX, GR and G6PD were also reduced in fish fed the FMXOS diet. Comparison of the present results with other studies performed in fish was not possible, as to the authors' knowledge there are no studies available regarding the effect of XOS on antioxidant status. In type 2 diabetes mellitus rats, XOS also contributed to a reduction of CAT activity in erythrocyte samples, but not of SOD and GPX activities ${ }^{(26)}$. The lower effects of XOS on the antioxidant enzymatic activity observed in fish fed the PF diets might be related to soyabean oligosaccharides that may have acted as prebiotics and masked the XOS effects ${ }^{(54-56)}$.

In mammals, prebiotics fermentation by gut microbiota leads to the production of SCFA, which have a role in oxidative stress modulation. In addition, butyrate, more than other SCFA, was reported as being related with a significant reduction in $\mathrm{H}_{2} \mathrm{O}_{2^{-}}$ induced DNA damage in rats and humans ${ }^{(57-59)}$. Although fish have a less abundant gut microbiota than mammals and lack a large bowel, it is known that fermentation by fish gut microbiota also produces SCFA ${ }^{(60)}$. Nonetheless, the reported antioxidant ability of XOS is most likely related to its composition, as most of the oligomers present in XOS consist of ester-linked phenolic acids such as ferulic, coumaric and caffeic acids ${ }^{(9,10,25)}$. Ferulic acid has potent antioxidant potential mainly because of its phenolic nucleus and extended side-chain conjugation that readily forms stabilised phenoxy radicals and terminate chain reactions ${ }^{(25)}$. In fact, ferulic acid scavenges superoxide anion radicals in a similar way to $\mathrm{SOD}^{(61)}$.

FOS or a combination of FOS and probiotics were already reported as having antioxidant capabilities in several fish species ${ }^{(18,19,21,62,63)}$. Zhang et al. ${ }^{(62)}$ explained this antioxidant potential of FOS by its bifidogenic effect and suggested that the antioxidant properties of FOS might help in the gut microbial defence mechanism, as FOS may help surpassing both exogenous and endogenous oxidative stress. Another possibility is that FOS might have a role in the translation and posttranslational process of the antioxidant enzymes ${ }^{(21)}$. However, further investigation is needed to understand the mechanisms behind FOS antioxidant capabilities. In the present study, except for a decrease of SOD activity in fish fed the PFFOS diet, scFOS had little effect in European sea bass oxidative status.

In conclusion, PF-based diets increased LPO levels and had negative impacts in the histomorphology of DI compared with fish fed FM-based diets. Prebiotic incorporation in PF diets was not effective in counterbalancing the negative effects of PF diets in gut morphology. However, XOS incorporation in both PF and FM diets reduced antioxidant enzymatic activity, suggesting a role in the reduction in ROS production.

\section{Acknowledgements}

The authors would like to express their thanks to Pedro Correia for the assistance during fish rearing. The authors would also like to thank Jefo Species-specific additives France, for providing the short-chain fructo-oligosaccharides prebiotic.
This work was partially funded by Projects AQUAIMPROV (reference NORTE-07-0124-FEDER-000038) and PEst-C/MAR/ LA0015/2011, co-financed by the North Portugal Regional Operational Programme (ON.2-O Novo Norte), under the National Strategic Reference Framework, through the European Regional Development Fund, and through the COMPETE Operational Competitiveness Programme and national funds through FCT - Foundation for Science and Technology, respectively. I. G., A. P.-J., A. C. and P. E. were supported by grants (SFRH/BD/76139/2011, SFRH/BPD/64684/2009, BD/ $47495 / 2008$ and BPD/39688/2007, respectively) from FCT, Portugal. The funder had no role in the design, analysis or writing of this article.

A. O.-T. and P. E. designed and coordinated the study. I. G, A. C., A. P.-J. and P. E. were responsible for the data collection, analysis and statistical analysis. All authors contributed to the interpretation of the data. I. G. wrote the first draft of the manuscript and all authors critically reviewed and revised the manuscript.

The authors have no conflicts of interest.

\section{References}

1. Tacon AGJ \& Hasan MR (2011) Demand and Supply of Feed Ingredients for Farmed Fish and Crustaceans. Trends and Prospects. Fisheries and Aquaculture Technical Paper, no. 564. Rome: FAO.

2. Gatlin DM III, Barrows FT, Brown P, et al. (2007) Expanding the utilization of sustainable plant products in aquafeeds: a review. Aquac Res 38, 551-579.

3. Gibson GR \& Roberfroid MB (1995) Dietary modulation of the human colonie microbiota: introducing the concept of prebiotics. J Nutr 125, 1401-1412.

4. Merrifield DL, Dimitroglou A, Foey A, et al. (2010) The current status and future focus of probiotic and prebiotic applications for salmonids. Aquaculture 302, 1-18.

5. Dimitroglou A, Merrifield DL, Carnevali O, et al. (2011) Microbial manipulations to improve fish health and production - a Mediterranean perspective. Fish Shellish Immunol 30, $1-16$.

6. Ring $\varnothing$ E, Olsen RE, Gifstad T $\varnothing$, et al. (2010) Prebiotics in aquaculture: a review. Aquac Nutr 16, 117-136.

7. Ring $\varnothing \mathrm{E}$, Dimitroglou A, Hoseinifar SH, et al. (2014) Prebiotics in Finfish: an update. In Aquaculture Nutrition: Gut Health, Probiotics and Prebiotics, pp. 360-400 [DL Merrifield and E Ring $\varnothing$, editors]. Chichester: John Wiley \& Sons, Ltd.

8. Bornet FRJ, Brouns F, Tashiro Y, et al. (2002) Nutritional aspects of short-chain fructooligosaccharides: natural occurrence, chemistry, physiology and health implications. Dig Liver Dis $\mathbf{3 4}$, S111-S120.

9. Broekaert WF, Courtin CM, Verbeke K, et al. (2011) Prebiotic and other health-related effects of cereal-derived arabinoxylans, arabinoxylan-oligosaccharides and xylooligosaccharides. Crit Rev Food Sci Nutr 51, 178-194.

10. Veenashri BR \& Muralikrishna G (2011) In vitro anti-oxidant activity of xylo-oligosaccharides derived from cereal and millet brans - a comparative study. Food Chem 126, 1475-1481.

11. Dimitroglou A, Merrifield DL, Moate R, et al. (2009) Dietary mannan oligosaccharide supplementation modulates intestinal microbial ecology and improves gut morphology of rainbow trout, Oncorbynchus mykiss (Walbaum). J Anim Sci 87, 3226-3234. 
12. Dimitroglou A, Merrifield DL, Spring P, et al. (2010) Effects of mannan oligosaccharide (MOS) supplementation on growth performance, feed utilisation, intestinal histology and gut microbiota of gilthead sea bream (Sparus aurata). Aquaculture 300, 182-188.

13. Dimitroglou A, Reynolds P, Ravnoy B, et al. (2011) The effect of mannan oligosaccharide supplementation on Atlantic Salmon smolts (Salmo salar L.) fed diets with high levels of plant proteins. J Aquac Res Dev S1-011 (Epublication 15 November 2011).

14. Zhou Q, Buentello JA \& Gatlin DM III (2010) Effects of dietary prebiotics on growth performance, immune response and intestinal morphology of red drum (Sciaenops ocellatus). Aquaculture 309, 253-257.

15. Hsu C-K, Liao J-W, Chung Y-C, et al. (2004) Xylooligosaccharides and fructooligosaccharides affect the intestinal microbiota and precancerous colonic lesion development in rats. J Nutr 134, 1523-1528.

16. López-Bote CJ, Diez A, Corraze G, et al. (2001) Dietary protein source affects the susceptibility to lipid peroxidation of rainbow trout (Oncorbynchus mykiss) and sea bass (Dicentrarchus labrax) muscle. J Anim Sci 73, 443-449.

17. Sitjà-Bobadilla A, Penña-Llopis S, Gómez-Requeni P, et al. (2005) Effect of fish meal replacement by plant protein sources on nonspecific defence mechanisms and oxidative stress in gilthead sea bream (Sparus aurata). Aquaculture 249, 387-400.

18. Li Y, Wang YJ, Wang L, et al. (2008) Influence of several non-nutrient additives on nonspecific immunity and growth of juvenile turbot, Scophthalmus maximus L. Aquac Nutr 14, 387-395.

19. Ai Q, Xu H, Mai K, et al. (2011) Effects of dietary supplementation of Bacillus subtilis and fructooligosaccharide on growth performance, survival, non-specific immune response and disease resistance of juvenile large yellow croaker, Larimichthys crocea. Aquaculture 317, 155-161.

20. Olsvik PA, Torstensen BE, Hemre GI, et al. (2011) Hepatic oxidative stress in Atlantic salmon (Salmo salar L.) transferred from a diet based on marine feed ingredients to a diet based on plant ingredients. Aquac Nutr 17, e424-e436.

21. Zhang C-N, Li X-F, Xu W-N, et al. (2013) Combined effects of dietary fructooligosaccharide and Bacillus licheniformis on innate immunity, antioxidant capability and disease resistance of triangular bream (Megalobrama terminalis). Fish Shellfish Immunol 35, 1380-1386.

22. Stoyanova S, Geuns J, Hideg É, et al. (2011) The food additives inulin and stevioside counteract oxidative stress. Int J Food Sci Nutr 62, 207-214.

23. Van den Ende W, Peshev D \& De Gara L (2011) Disease prevention by natural antioxidants and prebiotics acting as ROS scavengers in the gastrointestinal tract. Trends Food Sci Technol 22, 689-697.

24. Pejin B, Savic AG, Petkovic M, et al. (2014) In vitro anti-hydroxyl radical activity of the fructooligosaccharides 1-kestose and nystose using spectroscopic and computational approaches. Int J Food Sci Technol 49, 1500-1505.

25. Graf E (1992) Antioxidant potential of ferulic acid. Free Radic Biol Med 13, 435-448.

26. Sheu WH-H, Lee I-T, Chen W, et al. (2008) Effects of xylooligosaccharides in type 2 diabetes mellitus. J Nutr Sci Vitaminol 54, 396-401.

27. Gobinath D, Madhu AN, Prashant G, et al. (2010) Beneficial effect of xylo-oligosaccharides and fructo-oligosaccharides in streptozotocin-induced diabetic rats. Br J Nutr 104, 40-47.

28. Wang J, Cao Y, Wang C, et al. (2011) Wheat bran xylooligosaccharides improve blood lipid metabolism and antioxidant status in rats fed a high-fat diet. Carbohydr Polym 86, 1192-1197.
29. Association of Official Analytical Chemists (2000) Official Methods of Analysis of AOAC. Gaithersburg, MD: AOAC.

30. Beutler HO (1984) Starch. In Methods of Enzymatic Analysis, vol. 6, pp. 2-10 [HU Bergmeyer, editor]. Weinheim: Verlag Chemie.

31. Baeverfjord G \& Krogdahl ^ (1996) Development and regression of soybean meal induced enteritis in Atlantic salmon distal intestine. A comparison with the intestines of fasted fish. J Fish Dis 19, 375-387.

32. Krogdahl Å, Bakke-McKellep AM \& Baeverfjord G (2003) Effects of graded levels of standard soybean meal on intestinal structure, mucosal enzyme activities, and pancreatic response in Atlantic salmon (Salmo salar L.). Aquac Nutr 9, 361-371.

33. Penn MH, Bendiksen EÅ, Campbell P, et al. (2011) High dietary level of pea protein concentrate induces intestinal enteropathy in Atlantic salmon (Salmo salar L.). Aquaculture 310, 267-273.

34. Enes P, Pérez-Jiménez A, Peres H, et al. (2012) Oxidative status and gut morphology of white sea bream, Diplodus sargus fed soluble non-starch polysaccharide supplemented diets. Aquaculture 358-359, 79-84.

35. Bradford M (1976) A rapid and sensitive method for the quantitation of microgram quantities of protein using the principle of protein dye-binding. Anal Biochem 72, 248-254.

36. Guerreiro I, Oliva-Teles A \& Enes P (2015) Improved glucose and lipid metabolism in European sea bass (Dicentrarchus labrax) fed short-chain fructooligosaccharides and xylooligosaccharides. Aquaculture 441, 57-63.

37. Kaushik SJ, Covès D, Dutto G, et al. (2004) Almost total replacement of fish meal by plant protein sources in the diet of a marine teleost, the European seabass, Dicentrarchus labrax. Aquaculture 230, 391-404.

38. van den Ingh TSGAM, Krogdahl $\AA$, Olli JJ, et al. (1991) Effects of soybean-containing diets on the proximal and distal intestine in Atlantic salmon (Salmo salar): a morphological study. Aquaculture 94, 297-305.

39. Krogdahl Å, Bakke-Mckellep AM, Røed KH, et al. (2000) Feeding Atlantic salmon Salmo salar L. soybean products: effects on disease resistance (furunculosis), and lysozyme and IgM levels in the intestinal mucosa. Aquac Nutr 6, 77-84.

40. Refstie S, Storebakken T, Baeverfjord G, et al. (2001) Longterm protein and lipid growth of Atlantic salmon (Salmo salar) fed diets with partial replacement of fish meal by soy protein products at medium or high lipid level. Aquaculture 193, 91-106.

41. Opstvedt J, Aksnes A, Hope B, et al. (2003) Efficiency of feed utilization in Atlantic salmon (Salmo salar L.) fed diets with increasing substitution of fish meal with vegetable proteins. Aquaculture 221, 365-379.

42. Bonaldo A, Roem AJ, Fagioli P, et al. (2008) Influence of dietary levels of soybean meal on the performance and gut histology of gilthead sea bream (Sparus aurata L.) and European sea bass (Dicentrarchus labrax L.). Aquac Res 39, 970-978.

43. Couto A, Kortner TM, Penn M, et al. (2015) Saponins and phytosterols in diets for European sea bass (Dicentrarchus labrax) juveniles: effects on growth, intestinal morphology and physiology. Aquac Nutr 21, 180-193.

44. Hendriks HGCJM, VandenIngh TSGAM, Krogdahl A, et al. (1990) Binding of soybean agglutinin to small intestinal brush border membranes and brush border membrane enzyme activities in Atlantic salmon (Salmo salar). Aquaculture 91, 163-170.

45. Urán PA, Gonçalves AA, Taverne-Thiele JJ, et al. (2008) Soybean meal induces intestinal inflammation in common carp (Cyprinus carpio L.). Fish Shellfish Immunol 25, 751-760. 
46. Refstie S, Korsøen OJ, Storebakken T, et al. (2000) Differing nutritional responses to dietary soybean meal in rainbow trout (Oncorhynchus mykiss) and Atlantic salmon (Salmo salar). Aquaculture 190, 49-63.

47. Torrecillas S, Makol A, Caballero MJ, et al. (2007) Immune stimulation and improved infection resistance in European sea bass (Dicentrarchus labrax) fed mannan oligosaccharides. Fish Shellfish Immunol 23, 969-981.

48. Guerreiro I, Enes P, Rodiles A, et al. (2015) Effects of rearing temperature and dietary short-chain fructooligosaccharides supplementation on allochthonous gut microbiota, digestive enzymes activities and intestine health of turbot (Scophthalmus maximus L.) juveniles. Aquac Nutr (Epublication ahead of print version 12 February 2015).

49. Adom KK \& Liu RH (2002) Antioxidant activity of grains. J Agric Food Chem 50, 6182-6187.

50. Guo Q, Rimbach G, Moini H, et al. (2002) ESR and cell culture studies on free radical-scavenging and antioxidant activities of isoflavonoids. Toxicology 179, 171-180.

51. Halliwell B \& Gutteridge JMC (2007) Free Radicals in Biology and Medicine, 4th ed. New York: Oxford University Press.

52. Scott M, Zuo L, Lubin BH, et al. (1991) NADPH, not glutathione, status modulates oxidant sensitivity in normal and glucose-6-phosphate dehydrogenase-deficient erythrocytes. Blood 77, 2059-2064.

53. Pandolfi $\mathrm{P}$, Sonatí F, Rivi R, et al. (1995) Targeted disruption of the housekeeping gene encoding glucose-6-phosphate dehydrogenase (G6PD): G6PD is dispensable for pentose synthesis but essential for defense against oxidative stress. EMBO J 14, 5209-5215.

54. Delzenne NM (2003) Oligosaccharides: state of the art. Proc Nutr Soc 62, 177-182.

55. Gibson GR, Probert HM, Van Loo J, et al. (2004) Dietary modulation of the human colonic microbiota: updating the concept of prebiotics. Nutr Res Rev 17, 259-275.
56. Swennen K, Courtin CM \& Delcour JA (2006) Non-digestible oligosaccharides with prebiotic properties. Crit Rev Food Sci Nutr 46, 459-471.

57. Abrahamse SL, Pool-Zobel BL \& Rechkemmer G (1999) Potential of short chain fatty acids to modulate the induction of DNA damage and changes in the intracellular calcium concentration by oxidative stress in isolated rat distal colon cells. Carcinogenesis 20, 629-634.

58. Rosignoli P, Fabiani R, De Bartolomeo A, et al. (2001) Protective activity of butyrate on hydrogen peroxide-induced DNA damage in isolated human colonocytes and HT29 tumour cells. Carcinogenesis 22, 1675-1680.

59. Toden S, Bird AR, Topping DL, et al. (2007) Dose-dependent reduction of dietary protein-induced colonocyte DNA damage by resistant starch in rats correlates more highly with caecal butyrate than with other short chain fatty acids. Cancer Biol Ther 6, 253-258.

60. Burr G, Hume M, Ricke S, et al. (2008) A preliminary in vitro assessment of GroBiotic ${ }^{\circledR}-\mathrm{A}$, Brewer's yeast and fructooligosaccharide as prebiotics for the red drum Sciaenops ocellatus. J Environ Sci Health B 43, 253-260.

61. Toda S, Kumura M \& Ohnishi M (1991) Effects of phenolcarboxylic acids on superoxide anion and lipid peroxidation induced by superoxide anion. Planta Med 57, $110-112$.

62. Zhang C-N, Tian H-Y, Li X-F, et al. (2014) The effects of fructooligosaccharide on the immune response, antioxidant capability and HSP70 and HSP90 expressions in blunt snout bream (Megalobrama amblycephala Yih) under high heat stress. Aquaculture 433, 458-466.

63. Guerreiro I, Pérez-Jiménez A, Costas B, et al. (2014) Effect of temperature and short chain fructooligosaccharides supplementation on the hepatic oxidative status and immune response of turbot (Scophthalmus maximus). Fish Shellfish Immunol 40, 570-576. 